P0051

\title{
DESIGN OF ALTERNATIVE WARNING SIGN AND PEDESTRIAN CONSPICUITY
}

\author{
Martina Vikova et al.
}

DOI 10.25039/x46.2019.PO051

\author{
from \\ CIE x046:2019 \\ Proceedings \\ of the \\ 29th CIE SESSION \\ Washington D.C., USA, June 14 - 22, 2019 \\ (DOI 10.25039/x46.2019)
}

The paper has been presented at the 29th CIE Session, Washington D.C., USA, June 14-22, 2019. It has not been peer-reviewed by CIE.

(c) CIE 2019

All rights reserved. Unless otherwise specified, no part of this publication may be reproduced or utilized in any form or by any means, electronic or mechanical, including photocopying and microfilm, without permission in writing from CIE Central Bureau at the address below. Any mention of organizations or products does not imply endorsement by the CIE.

This paper is made available open access for individual use. However, in all other cases all rights are reserved unless explicit permission is sought from and given by the $\mathrm{CIE}$.

CIE Central Bureau

Babenbergerstrasse 9

A-1010 Vienna

Austria

Tel.: +4317143187

e-mail: ciecb@cie.co.at

www.cie.co.at 


\title{
DESIGN OF ALTERNATIVE WARNING SIGN AND PEDESTRIAN CONSPICUITY
}

\author{
Viková, M. ${ }^{1}$, Zelová, K. ${ }^{2}$, Kuzmová, M. ${ }^{2}$, Vik, M. ${ }^{1}$, Havelka, A. ${ }^{2}$ \\ ${ }^{1}$ Laboratory Color and Appearance Measurement,Technical University of Liberec,CZECH REPUBLIC, \\ 2 Department of Clothing Technology, Technical University of Liberec, CZECH REPUBLIC \\ martina.vikova@tul.cz
}

DOI 10.25039/x46.2019.PO051

\begin{abstract}
The aim of this paper is conspicuity of pedestrians during low visibility. Collisions between vehicles and pedestrians are a significant problem, and substantial evidence indicates that the problem is closely linked with low illumination. A less expensive approach to enhancing the conspicuity of pedestrians involves using retroreflective material - material that has been engineered to passively reflect light back in the direction of its source. This study showed the influence reflective material, and its various configurations, can have when trying to detect pedestrians at night. Visual detection of different design was compared with model of dominant contrast DC. The use of reflective treatments on clothing has been shown to enhance drivers' ability to detect pedestrians at night. On base realized analysis of received results is recommended number, size and placement of used retro-reflexive pattern on kids and teen outdoor cloths.
\end{abstract}

Keywords: e.g. conspicuity, high visibility, safety, spectrophotometry, colorimetry

\section{Introduction}

Safety on the road is very discussed topic of many research work. The improvement of number cars and their speed leads to risk of collision with pedestrians as in built up area, so also out of it. The most endangered group are generally children on higher level of basic schools and also middle school students. The design of high visibility clothing is based on two almost independent phenomena to increase its conspicuity. Fluorescent colorants that increase day visibility and retroreflective strips, which increase night visibility (Vik 2016). As for retroreflective materials, they appear brightest to an observer located near the original light source. Since very little light is scattered when the light is returned, retroreflective materials enhance the contrast of the wearer for an observer located near the original light source. Despite the benefits of both reflective clothing and headlight illumination, the problem of pedestrian detection and pedestrian overestimation at night still exists. Design of warning cloths is well known issue, nevertheless it is focused on special conditions following some rules related to traffic regulation. Outside of these conditions people doesn't prefer to wear it. Based on that mainly children or sportsman doing outdoor activities are protected insufficiently. Subsidiary effect for increasing of night conspicuity is made by phosphorescent design that allowing identification of pedestrians outside of illuminated area. Phosphorescence spectral effectiveness function allows computing of relative response of individual materials used as background of phosphorescent pigment and relating decay time of phosphorescent pattern (Vik 2013).

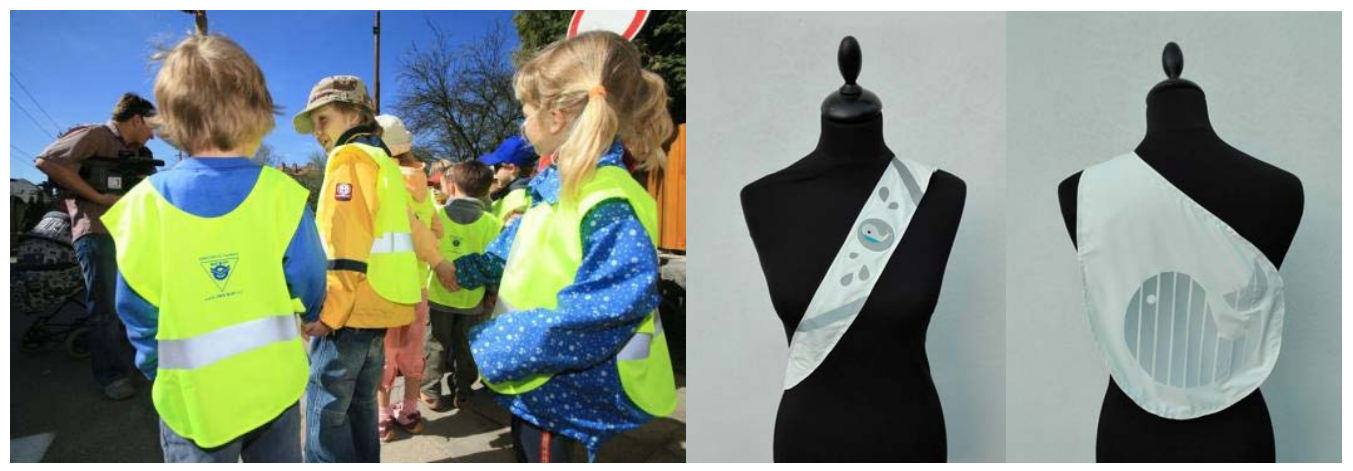

Figure 1 - Safety vest design vs safety design of fashionable bag 
Presented study is discussing alternative design allowing increasing of pedestrian conspicuity with use pedestrian contrast profile, dominant contrast DC respectively, found by Saraji and Oommen for various pedestrian locations (Saraiji 2015).

\section{Materials and methods}

The objective of this work is to examine the DC under local street condition with some disturbing light sources in horizon position including vertical illuminance from street lighting and contribution of car headlamps. Following this recommendation was used set of design where retroreflective parts are located on different positions of experimental jacket as visible on scheme in Tab. 1.

Table 1 - Caption of Table 1

\begin{tabular}{|c|c|c|c|c|c|}
\hline No. & Design & $\begin{array}{c}\text { Area } \\
{[\%]}\end{array}$ & No. & Design & $\begin{array}{c}\text { Area } \\
{[\%]}\end{array}$ \\
\hline 1 & & 8.7 & 2 & & 7.4 \\
\hline 3 & & 24.4 & 4 & & 16.0 \\
\hline 5 & & 21.7 & 6 & & 32.6 \\
\hline 7 & & 30.4 & 8 & & 23.7 \\
\hline 9 & & 30.2 & 10 & & 8.7 \\
\hline 11 & & 38.2 & 12 & 1 & 47.4 \\
\hline
\end{tabular}

For the purpose of this experiment was prepared cases study and after of market investigation we select 8 variants of kid's windbreaker, the 4 variants windbreakers with hood and 4 variants 
without hood. Selected windbreakers are designed according present fashion trends with different size, shape and placement on the windbreaker and amount of retro reflective materials. For experiment we use 3 type of retro reflective materials. Length piping inset with segmentation of parts, retro reflective foil applicable by sewing or ironing.

Measurements also include 2 kid's windbreakers and two type of complements. Totally we test 12 variants of kid's windbreakers and complements.

Conspicuity of different alternative warning signs was tested visually in two street lighting scenarios: a) unlit local road in winter time with car headlights only, b) lit street with car headlights, with use of panel of five observers. The street was illuminated with poles that are 14 meters high and 50 meters apart using LED of CCT $4000 \mathrm{~K}$ and spill control optics. Along the longitudinal direction of the street were chosen three distances from car: 50,100 and $200 \mathrm{~m}$. The car used during test was Peugeot 307 CC Cabrio with Xenon headlamps and both - low and high beam illumination was tested. As luminance measuring video photometer was used Nikon D70 digital camera equipped with zoom lens 70-300 mm connected with laptop including LCAM software under MATLAB platform. Each of twelve different alternative design was applied on small size jacket and dressed on manikin with high of $150 \mathrm{~cm}$ positioned in distance $1.5 \mathrm{~m}$ from right edge of street. Vertical illuminance levels were found at various longitudinal and lateral points along the street at 3 different heights $0.5 \mathrm{~m}, 1 \mathrm{~m}$ and $1,5 \mathrm{~m}$ above ground. Same point was used for control measurement of diffuse reflectance target (Zenith Lite ${ }^{\mathrm{TM}}$ ) with spectroradiometer PhotoResearch PR740.

Dominant contrast DC was computed based as average value contrast value of 12 significant point on front part and 12 significant point on the back part of tested design. The contrast $C$ of each significant point (i) was obtained by using equation:

$$
C_{i}=\frac{L_{T i}-L_{B i}}{L_{B i}}
$$

where $L_{T i}$ is the tested design (pedestrian) luminance at point $i$, and $L_{B i}$ is the background luminance near to point $i$.

\section{Results and discussion}

The measurements carried out in laboratory and during first therein measurements shows to us that the highest coefficient of retro reflection from both sides had variants 11 and 12 , which in conditions of reduced distance are $750 \mathrm{~cd} . \mathrm{m}^{2} . \mathrm{Ix}^{-1}$, length piping had $250 \mathrm{~cd} \cdot \mathrm{m}^{2} \mathrm{Ix} \mathrm{x}^{-1}$. The worst result showed the thin strips, when coefficient of retroreflection was only $120 \mathrm{~cd} \cdot \mathrm{m}^{2} \mathrm{Ix}^{-1}$.

Here summarize the results. To the maximum conspicuity was found with so called biomotion design and arrangement which accent the human silhouette contrary to simple circle or rectangular patterns with the similar retroreflective area. Street lighting contributed most to the Illuminance values at $1.5 \mathrm{~m}$ high than at other heights.

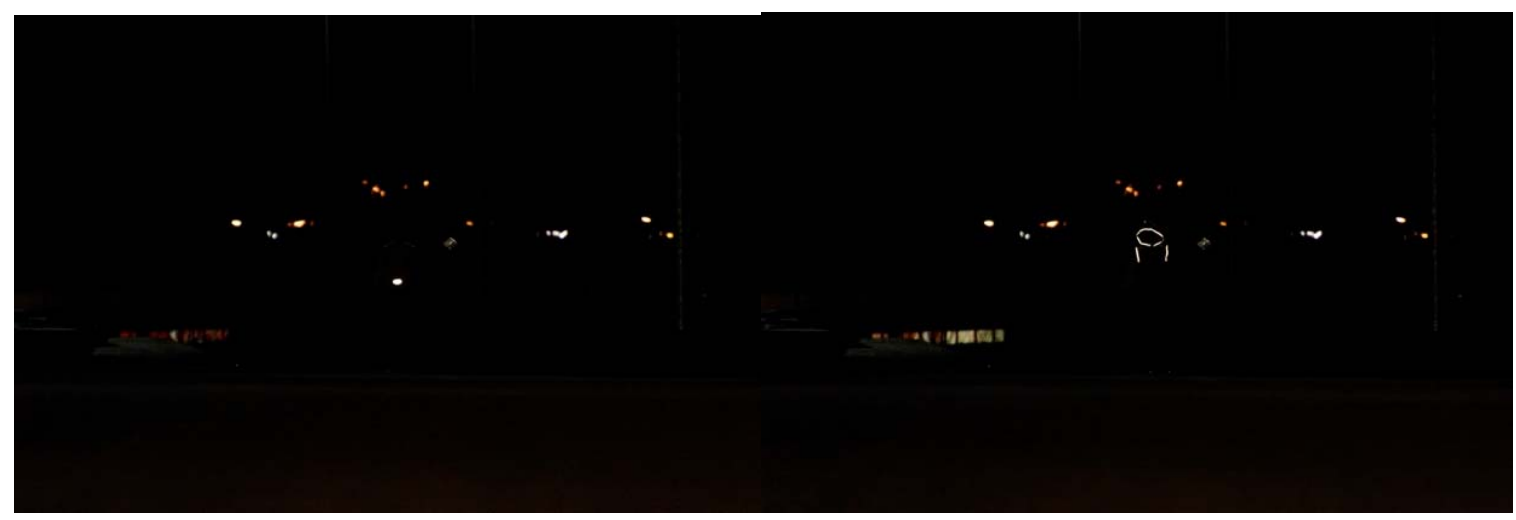

Figure 2 - An example of two warning design conspicuity - distance $100 \mathrm{~m}$ and low beam

And is effective mainly on the parts of jacket with diffuse reflectance than with retroreflective signs. The other two control points ( 0.5 and $1 \mathrm{~m}$ height above ground) were greatly affected by 
the car headlamps and in point of view of retroreflective sign arrangements appear bottom part of tested jacket as most effective. Dominant contrast due to car headlights changed as a function of the distance between the car and beam mode (high or low). It was also confirmed that the dominant contrast due to car headlights combined with streetlights gave larger DC values than due to car headlights alone.

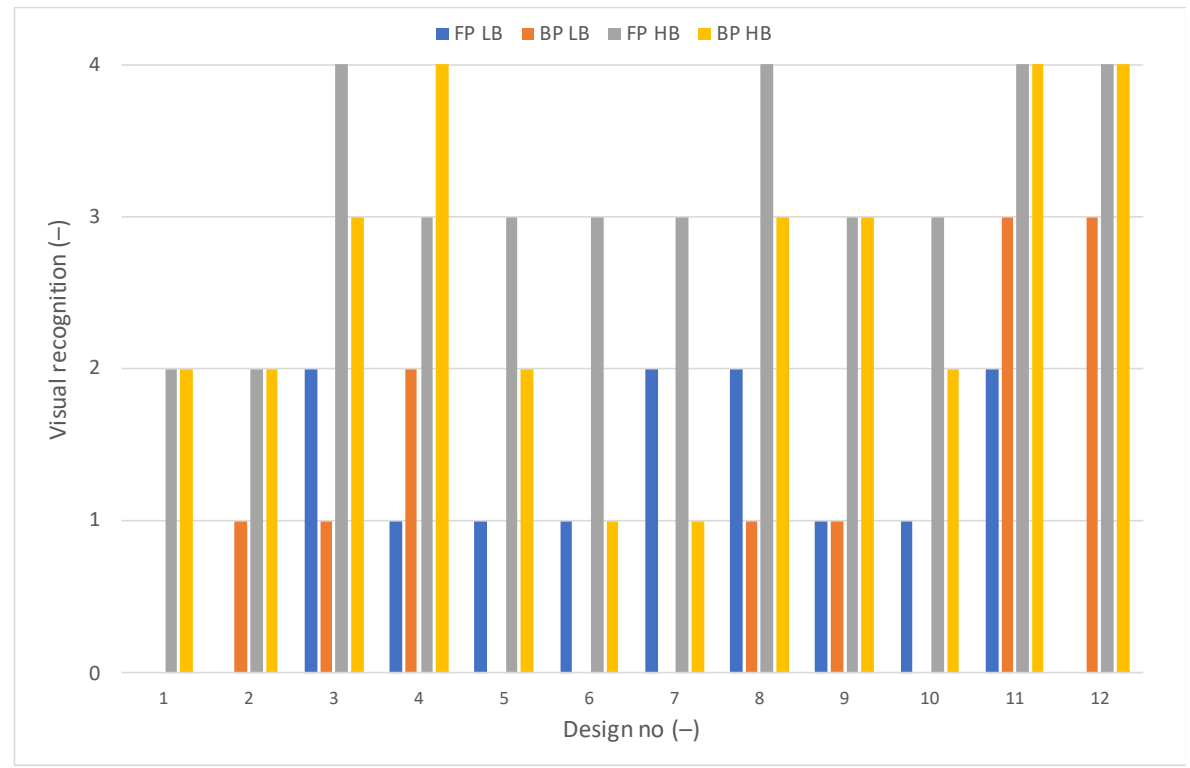

Figure 3 - Visual recognition of different tested design - distance $50 \mathrm{~m}$ (FP - front part, BP - back part, LB - low beam, HB - high beam)

From all realized measurements is evident that the best results had the complement with num. 11 and 12 for back part. For kid's windbreakers we found the best results for num.7, 8, and 9 variants. For kid's windbreaker num.10 is visibility provide by leading of retro reflexive strips around armhole and around hood from directions for shorter distance $50 \mathrm{~m}$.

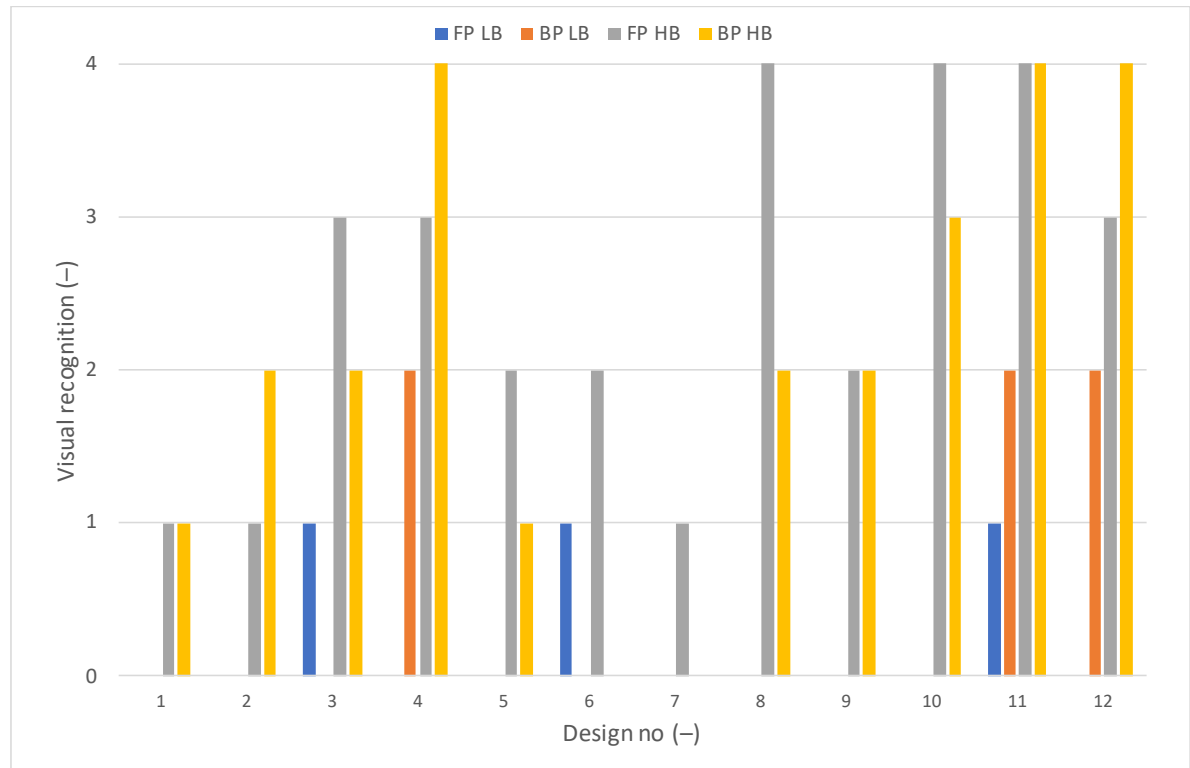

Figure 4 - Visual recognition of different tested design - distance $100 \mathrm{~m}$ (FP - front part, BP - back part, LB - low beam, HB - high beam)

For kid's windbreakers num. 7 and 8 are retro reflexive elements leads around all length of sleeves or in area of knuckle. Is also evident that placement of retro reflexive elements in movable area was more effective and there are quicker reactions of respondent drivers against statically placement. The worst results were obtained for variants 1 and 2 . 


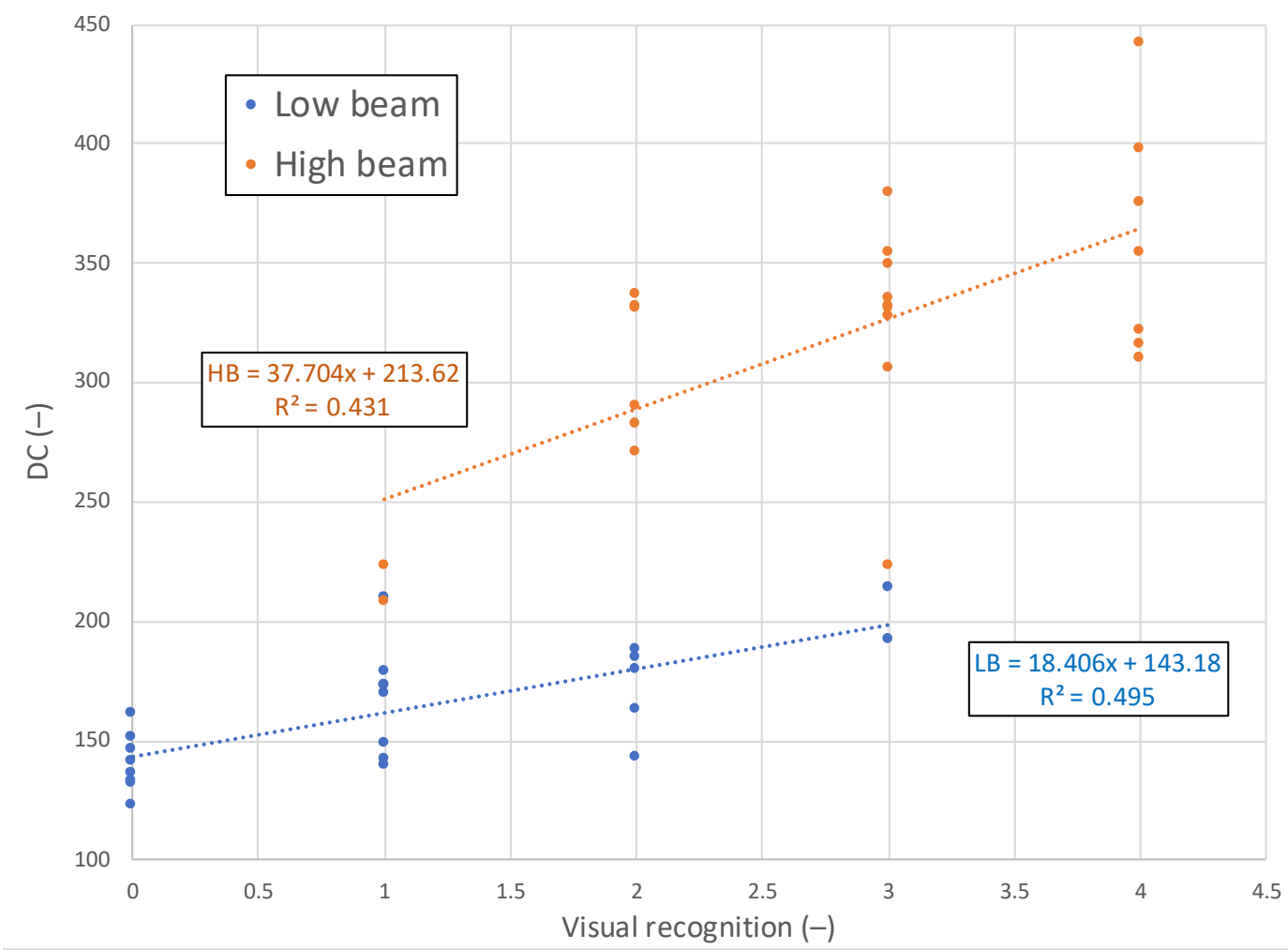

Figure 5 - Relationship between dominant contrast DC and visual recognition - distance $50 \mathrm{~m}$

If we compare obtained results from visual recognition during therein test with dominant contrast, it is visible that high beam increase DC as expected and also conspicuity of tested design. In point of view of low beam is important for designers that retroreflective pattern need to fulfill more than 225 units of DC. Bellow this limit is difficult for drivers to recognize pedestrians who are walking on the border of road.

These are the kid's windbreakers, that are represent the present offer on the market with retro reflexive materials. Reason is insufficient amount, area of retro reflexive materials and static placement on the windbreaker. The responded have referred that the retro reflective elements disappear in street lighting and the retro reflective elements are not fully visible. After these results we recommend the placement the retro reflective elements on sleeve in diagonal directions. Placement on the hood is only design element but if we take in consideration the other design for example the arrow it could be also solution for effective designing. Placement of retro reflexive elements according all length part of windbreaker helps to quick reaction of driver respondent to person on the road. Our recommendation is also directed to avoid retro reflective elements on static part of body that is visible as points and they blend with street lights.

\section{Conclusion}

This study showed the influence reflective material, and its various configurations, can have when trying to detect pedestrians at night. The use of reflective treatments on clothing has been shown to enhance drivers' ability to detect pedestrians at night. In congruence with recent studies have further explored this topic of reflective clothing and have looked into the effects of reflective material placement and arrangements including reflective vests and biological motion configurations.

In addition to clothing, headlight illumination has also been shown to both positively and negatively affect a driver's detection of pedestrians at night. Although headlights may provide more illumination and contrast, the glare from headlights of oncoming cars may interfere with drivers' abilities to detect pedestrians, particularly those wearing clothing that does not provide substantial contrast. It was found that mainly individual retroreflective patterns are less visible than simple strips following biomotion design. The Dominant Contrast could be a useful metric in street lighting design as well as night time visibility studies. 


\section{References}

[1] SARAIJI, R. \& OOMMEN, M.S., 2015. Dominant contrast as a metric for the lighting of pedestrians. Lighting Research \& Technology, 47(4), pp.434-448.

[2] VIK, M., VIKOVÁ, M. \& KASPAROVA, M., 2013. Decay of Phosphorescent Warning Design on Textile Substrates. Applied Mechanics and Materials, 440, pp.112-117.

[3] VIK, M. et al., 2016. Measuring Techniques for Retroreflectivity Levels of Small Signs. Defect and Diffusion Forum, 368, pp.193-197. 